\title{
Primitive ventricle with normally related great vessels and stenotic subpulmonary outlet chamber Angiographic differentiation from tetralogy of Fallot
}

\author{
MICHAEL G. SAALOUKE, LOWELL W. PERRY, EDWIN O. OKOROMA, \\ STEPHEN R. SHAPIRO, AND LEWIS P. SCOTT, III \\ From the Department of Cardiology, Children's Hospital National Medical Center and the Department of \\ Child Health and Development, The George Washington University School of Medicine, Washington, D.C., \\ U.S.A.
}

Four patients with primitive ventricle and normally related great vessels with stenotic subpulmonary outlet chamber (Holmes' heart with pulmonary stenosis) are reported. The history, physical examination, and chest $\mathrm{x}$-ray film are not helpful in distinguishing Holmes' heart with pulmonary stenosis from tetralogy of Fallot. Electrocardiogram often provides the first clue to the presence of Holmes' heart; left axis deviation with or without left ventricular hypertrophy is an unusual finding in tetralogy of Fallot, but common in Holmes' heart. Selective ventriculography is diagnostic: the right ventricular outflow chamber overlies the aortic root and aortic valve in the frontal view in Holmes' heart with pulmonary stenosis, but is to the left of the aortic valve in tetralogy of Fallot; no ventricular septum can be identified in Holmes' heart. The diagnosis can be suspected in a child with clinical features of tetralogy of Fallot but atypical electrocardiogram, and can be established by angiography.

Single ventricle accounts for 2 to 3 per cent of congenital heart disease (Abbott, 1936; Fontana and Edwards, 1962) and is usually associated with transposition of the great vessels (Elliott et al., 1963). In 10 to 15 per cent of cases, the great arteries are normally related. Single ventricle with normally related vessels was first described by Holmes in 1824 (Holmes, 1901). The features of the case described by Holmes include a single ventricle receiving two separate atrioventricular valves and giving rise to normally related great vessels. The morphology of the single ventricle in all cases of Holmes' heart to date has been left ventricle, corresponding to type A single ventricle of Van Praagh (Van Praagh et al., 1964). Embryologically, the ventricular malformation of type A single ventricle is absence of the right ventricular sinus (body or inflow).

Pulmonary stenosis is frequently associated with Holmes' heart. There is a striking clinical similarity between Holmes' heart with pulmonary stenosis and tetralogy of Fallot (Rosenquist et al., 1963; Klaus et al., 1969; Rao and Edwards, 1974). This review of published papers and report of our own 4 cases is prompted by our experience with a patient with Holmes' heart and pulmonary stenosis Received for publication 1 March 1977 who was sent to operation with the erroneous diagnosis of tetralogy of Fallot. The purpose of this paper is to present these cases and to discuss the distinguishing diagnostic features of the lesion. We use the term 'Holmes' heart with pulmonary stenosis' to describe primitive ventricle with normally related great vessels and stenotic subpulmonary outlet chamber.

\section{Clinical material}

Four cases of Holmes' heart with pulmonary stenosis seen at Children's Hospital National Medical Center were reviewed. The diagnosis was confirmed at necropsy in 1 and by angiography in 3 cases. Each of the 4 patients had 2 normal atrioventricular valves, a single ventricle with normally related great vessels, and pulmonary stenosis. Clinical $x$-ray, electrocardiographic, and haemodynamic data were available in each of the 4 patients.

\section{Results}

\section{CLINICAL FEATURES}

(Table 1) Of the 4 patients, 3 were female. Case 1 died at the age of $6 \frac{1}{2}$ years, but the other 3 
patients are still alive. All 4 patients had symptoms: cyanosis was present at birth in 2 patients, developed in the first year of life in another, and became apparent at 4 years of age in the fourth; two patients had hypoxic spells before the age of 2 years. The first heart sound was normal in all 4 patients; the second heart sound was single in 3, and normally split in 1. A grade 3 to $4 / 6$ ejection type of systolic murmur was heard along the left sternal border in each patient and was associated with a thrill in 2. None of the patients had a mid-diastolic murmur.

\section{RADIOGRAPHIC FINDINGS}

(Table 1 and Fig 1). The heart size was normal in 3 patients and slightly increased in 1 . The aortic arch was on the left in all patients. The pulmonary vascularity was decreased in 2 , normal in 1 , and slightly increased in 1 .

\section{ELECTROCARDIOGRAPHIC FINDINGS}

(Table 2 and Fig 2). Sinus rhythm was present in all patients. There was left axis deviation in 2, right axis deviation in 1 , and a normal axis in 1 . Left ventricular hypertrophy was present in 3 patients and right ventricular hypertrophy in 1 . One patient (case 3) showed intermittent left bundle-branch block. Frank vectorcardiograms were recorded in 2 and confirmed diminished anterior forces in the $\mathbf{Z}$ axis.

Table 1 Clinical findings in 4 patients with Holmes' heart and pulmonary stenosis

\begin{tabular}{|c|c|c|c|c|}
\hline \multirow[t]{2}{*}{ Physical examination } & \multicolumn{4}{|c|}{ Case No. } \\
\hline & 1 & 2 & 3 & 4 \\
\hline $\begin{array}{l}\text { Age } \\
\text { Sex } \\
\text { Cyanosis } \\
\text { Dyspnoea } \\
\text { Normal first heart sound } \\
\text { Single second heart sound } \\
\text { Systolic murmur, lower sternal } \\
\quad \text { border } \\
\text { Thrill, left sternal border }\end{array}$ & $\begin{array}{l}4 \text { yr } \\
\text { F } \\
+ \\
+ \\
+ \\
- \\
+ \\
+\end{array}$ & $\begin{array}{l}3 \text { m } \\
\mathbf{F} \\
+ \\
+ \\
+ \\
+ \\
+ \\
+\end{array}$ & $\begin{array}{l}7 \mathrm{~m} \\
\mathrm{~F} \\
+ \\
+ \\
+ \\
+ \\
-\end{array}$ & $\begin{array}{l}15 \mathbf{y} \\
\mathbf{M} \\
+ \\
+ \\
+ \\
+ \\
+ \\
+\end{array}$ \\
\hline $\begin{array}{l}\text { Chest } x \text {-ray film } \\
\text { Cardiomegaly } \\
\text { Pulmonary vascularity } \\
\text { Left aortic arch }\end{array}$ & $\begin{array}{l}+ \\
\uparrow \\
+\end{array}$ & $\begin{array}{l}- \\
\text { Normal } \\
+\end{array}$ & $\begin{array}{l}\bar{\downarrow} \\
+\end{array}$ & $\begin{array}{l}\bar{\downarrow} \\
+\end{array}$ \\
\hline
\end{tabular}

*+, present; -, absent; $\uparrow$, increased; $\downarrow$, decreased.

Table 2 Electrocardiographic findings

\begin{tabular}{lll}
\hline Case No. & QRS axis & Chamber hypertrophy \\
\hline 1 & -15 & Left ventricle \\
2 & +45 & Left ventricle \\
3 & -15 & Left ventricle, right atrium \\
4 & +110 & Right ventricle \\
\hline
\end{tabular}

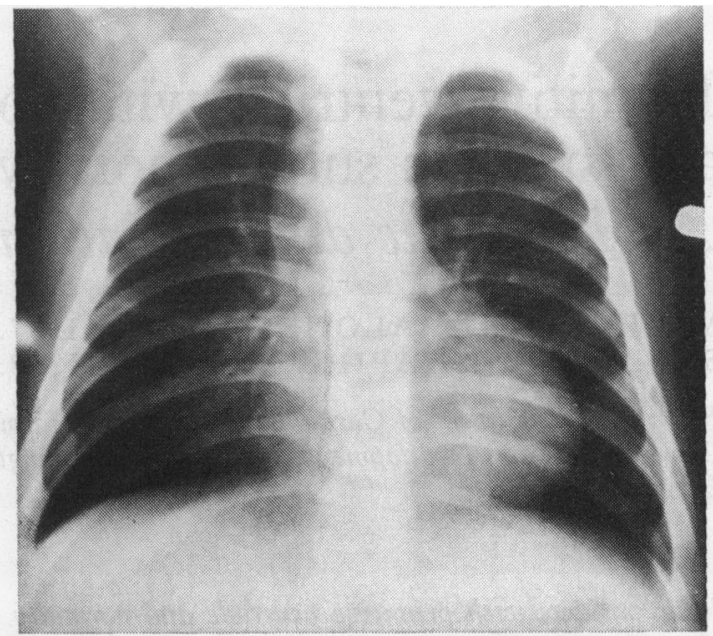

Fig. 1 Chest $\mathrm{x}$-ray film of case 2 showing normal heart size and upturned apex suggesting right ventricular hypertrophy. The pulmonary artery segment is decreased and the pulmonary vascularity is normal.

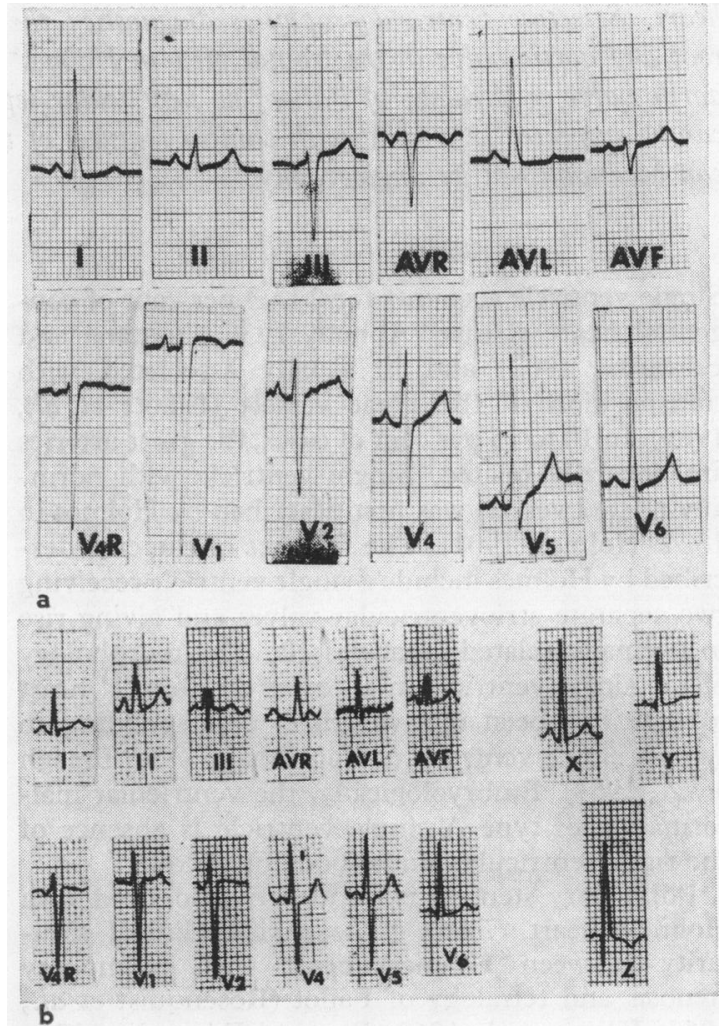

Fig. 2 (a) Electrocardiogram of case 1 showing left axis deviation $\left(-15^{\circ}\right)$ and 'left ventricular hypertrophy'; (b) electrocardiogram of case 2 showing normal axis $\left(+45^{\circ}\right)$ and prominent posterior forces. The Frank vectorcardiogram shows decreased anterior forces in $Z$ axis. 
CARDIAC CATHETERISATION FINDINGS

(Table 3). Aortic oxygen saturation ranged from 69 to 89 per cent. The pulmonary artery could not be entered in 2 patients; in the other 2 , there were gradients of 100 and $115 \mathrm{mmHg}$ between the pulmonary artery and the ventricular chamber. The aortic systolic pressure was identical to the ventricular systolic pressure in each patient.

\section{ANGIOGRAPHIC FINDINGS}

The angiograms correctly identified the presence of single ventricle with left ventricular morphology (smooth-walled), normally related great vessels, 2 distinct atrioventricular valves, and subpulmonary outlet chamber in 3 patients. One patient was initially thought to have tetralogy of Fallot (case 1), but in retrospect the angiographic findings of Holmes' heart were recognised. The angiographic features were as follows: (1) there was one ventricular chamber with left ventricular morphology; (2) there was simultaneous filling of both great vessels; (3) the pulmonary artery was displaced to the right of its usual position (Fig. 3a); (4) the pulmonary artery and aorta appeared to be more directly anterior and posterior than usual on the frontal view; (5) obstruction was present beneath the pulmonary valve in the infundibulum or at the bulboventricular foramen; (6) absence of the ventricular septum was noted on the left anterior oblique view; (7) the right ventricular outflow chamber was located anteriorly and superiorly and transversed the root of the aorta and the aortic valve in the posteroanterior view (Fig. 3a, 4).

\section{COURSE AND TREATMENT}

One patient died after operation at the age of $6 \frac{1}{2}$ years from ventricular arrhythmia; pathological examination (Fig. 5) confirmed the diagnosis. Two patients had palliative systemic-pulmonary anastomoses for hypoxic spells and are alive. One patient is well without surgical treatment.

\section{Discussion}

Thirty-five cases of single ventricle with normally related great vessels have been previously reported (Rosenquist et al., 1963; Anselmi et al., 1968; Klaus et al., 1969; Lev et al., 1969; Edie et al., 1973; Marin-Garcia et al., 1974). Though the case originally described by Holmes did not have pulmonary stenosis, approximately 50 per cent of reported cases of Holmes' heart have had associated pulmonary stenosis. The pulmonary stenosis is subpulmonary in approximately 80 per cent of cases, though valvar stenosis may be present either alone or in association with subpulmonary obstruction. Of the reported cases 70 per cent have been female.

When Holmes' heart is associated with pulmonary stenosis, the clinical presentation, the chest $x$-ray appearances, the catheterisation data, and the angiographic features resemble those of tetralogy of Fallot. Thirteen (37\%) of 35 cases reported were diagnosed as tetralogy of Fallot. Chest $x$-ray films in both lesions may be identical. There are no distinguishing features in the presence of a left aortic arch. Right aortic arch has not been reported in association with Holmes' heart, but is present in approximately 25 per cent of cases of tetralogy of Fallot.

The clinical distinction between Holmes' heart with pulmonary stenosis and tetralogy of Fallot can often be made by examining the electrocardiogram. In Fallot's tetralogy, right ventricular hypertrophy and right axis deviation are the major electrocardiographic manifestations. The QRS axes of 18 patients with Holmes' heart with pulmonary stenosis have been described (Fig 6). Of the 18 patients, $10(55 \%)$ had extreme left axis deviation $\left(0^{\circ}\right.$ to $\left.-180^{\circ}\right), 3(17 \%)$ cases had a normal axis varying from $0^{\circ}$ to $\pm 45^{\circ}$ (which is further to the left than is usual in tetralogy of Fallot), and 5 cases $(28 \%)$ had right axis deviation $\left(+95^{\circ}\right.$ to $\left.+120^{\circ}\right)$. Marín-Garcia et al. (1974) found no correlation

Table 3 Haemodynamic findings

\begin{tabular}{|c|c|c|c|c|c|c|c|c|}
\hline \multirow[t]{2}{*}{ Sites } & \multicolumn{2}{|l|}{ Case 1} & \multicolumn{2}{|l|}{ Case 2} & \multicolumn{2}{|l|}{ Case 3} & \multicolumn{2}{|l|}{ Case 4} \\
\hline & $\begin{array}{l}\mathrm{O}_{2} \text { saturation } \\
\text { (per cent) }\end{array}$ & $\begin{array}{l}\text { Pressure } \\
(\mathrm{mmHg})\end{array}$ & $\begin{array}{l}\mathrm{O}_{2} \text { saturation } \\
\text { (per cent) }\end{array}$ & $\begin{array}{l}\text { Pressure } \\
(\mathrm{mmHg})\end{array}$ & $\begin{array}{l}\mathrm{O}_{2} \text { saturation } \\
\text { (per cent) }\end{array}$ & $\begin{array}{l}\text { Pressure } \\
(\mathrm{mmHg})\end{array}$ & $\begin{array}{l}\mathrm{O}_{2} \text { saturation } \\
\text { (per cent })\end{array}$ & $\begin{array}{l}\text { Pressure } \\
(\mathrm{mmHg})\end{array}$ \\
\hline $\begin{array}{l}\text { Ventricle } \\
\text { Aorta }\end{array}$ & $\begin{array}{l}77 \\
83\end{array}$ & $\begin{array}{l}100 / 5 \\
100 / 60 \\
(75)\end{array}$ & $\begin{array}{l}86 \\
69\end{array}$ & $\begin{array}{l}100 / 8 \\
100 / 50 \\
(70)\end{array}$ & $\begin{array}{l}79 \cdot 5 \\
80\end{array}$ & $\begin{array}{l}80 / 9 \\
80 / 50 \\
(60)\end{array}$ & $\begin{array}{l}77 \\
83\end{array}$ & $\begin{array}{l}120 / 9 \\
120 / 65\end{array}$ \\
\hline Pulmonary artery & 78 & $\begin{array}{l}25 / 18 \\
(20)\end{array}$ & $\star$ & $\star$ & $\star$ & $\star$ & 77 & $8 / 5$ \\
\hline
\end{tabular}

* :pulmonary artery not entered. 


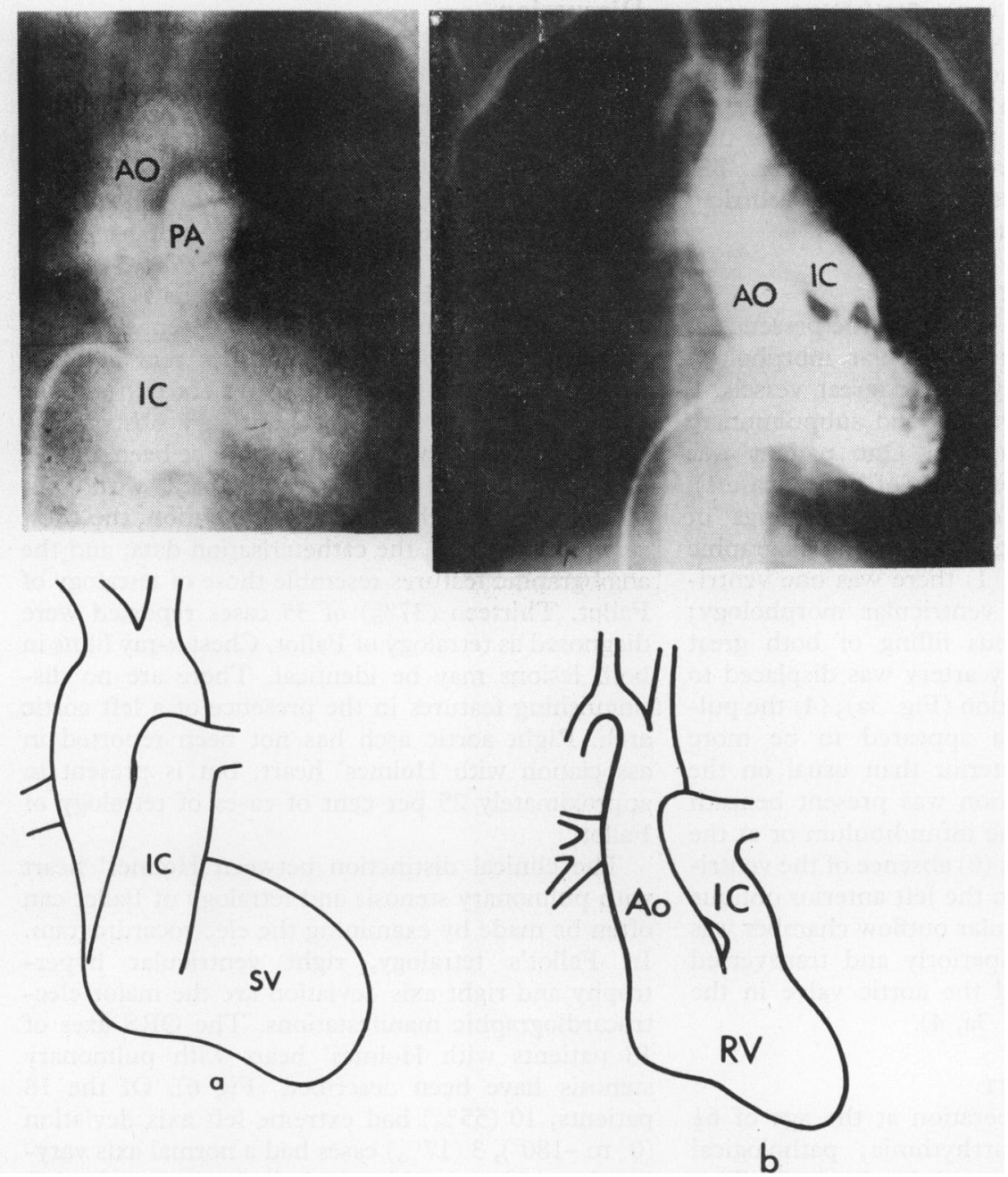

Fig. 3 (a) Ventriculogram in the anteroposterior view of case 1 with Holmes' heart and pulmonary stenosis showing the infundibular chamber (IC) overlying the aortic root valve. SV, single ventricle; Ao, aorta. (b) For comparison the ventriculogram in the anteroposterior view of a patient with tetralogy of Fallot showing the infundibular chamber located to the left of the aorta.

between the QRS axis and the presence or absence of pulmonary stenosis in patients with Holmes' heart. 'Left ventricular hypertrophy' was present in 70 per cent, 'right ventricular hypertrophy' in 20 per cent, and 'combined ventricular hypertrophy' in 10 per cent of cases in whom patterns of ventricular hypertrophy were reported (Fig. 6). Frank vectorcardiograms in 2 of our patients revealed diminished anterior forces in the $Z$ axis. Left axis deviation, with or without left ventricular hypertrophy, is an unusual finding in tetralogy of Fallot and should

Fig. 4 Ventriculogram of case 2 in the anteroposterior view showing the infundibular chamber (IC) which clearly overlies the aortic root. SV, single ventricle; $P A$, pulmonary artery; Ao, aorta.

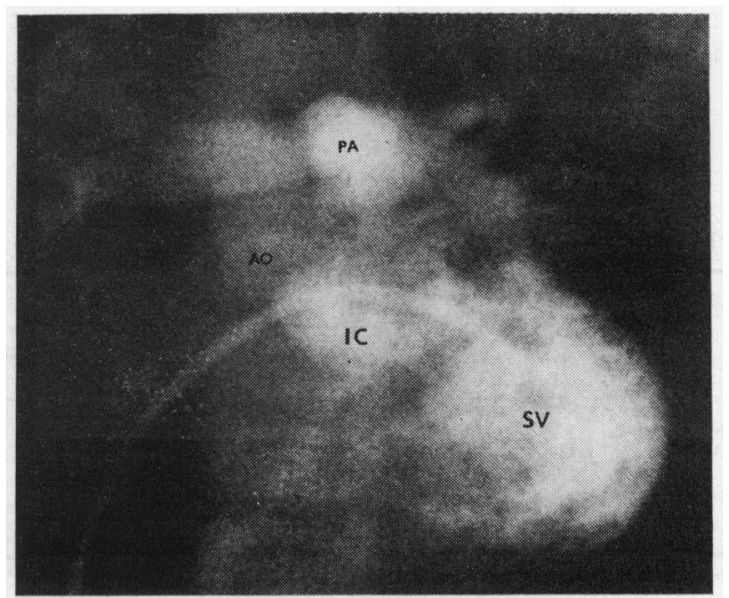




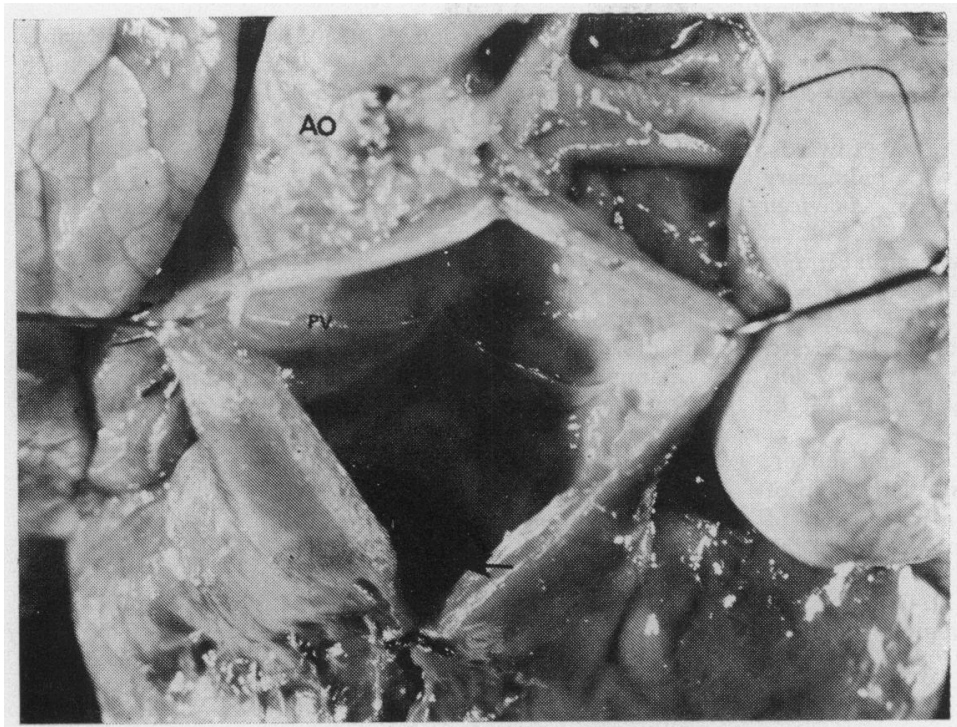

Fig. 5 Exterior of the heart of case 1, in the anteroposterior view. The outflow chamber and part of the pulmonary artery are exposed. The pulmonary valve (PV) and part of the bulboventricular foramen (arrow) can be seen. The outflow chamber cuts across the aortic root and the aortic valve. Ao, aorta.

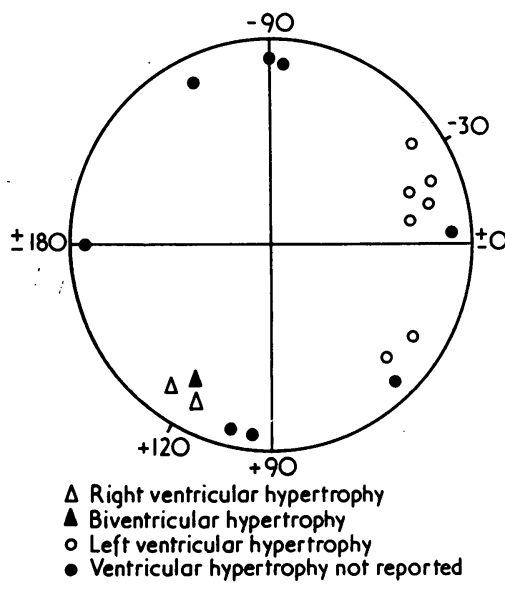

Fig. 6 The mean $Q R S$ axis in the frontal plane in 18 reported patients with single ventricle, normally related great vessels, and pulmonary stenosis (our 4 cases included).

suggest the presence of Holmes' heart with pulmonary stenosis, especially in a girl.

The definitive diagnosis of Holmes' heart with pulmonary stenosis depends on ventriculography. In Fallot's tetralogy, 2 distinct ventricles are usually seen, with separate atrioventricular valves. Absence of the ventricular septum in the left anterior oblique or lateral view is important in establishing the diagnosis of single ventricle. It must be kept in mind in this lesion that the chordae tendineae from both atrioventricular valves may arise from a common papillary muscle (Marín-Garcia et al., 1974) which may resemble a ventricular septum on the ventriculogram and, therefore, lead to the erroneous diagnosis of tetralogy of Fallot. In both lesions, simultaneous filling of the aorta and the pulmonary artery occurs. However, careful observation of the position of the infundibular chamber is helpful in distinguishing Holmes' heart with pulmonary stenosis from tetralogy of Fallot. In the frontal view, the infundibular chamber overlies the aortic valve and the aortic root in Holmes' heart, but is to the left of the aortic valve in tetralogy of Fallot (Fig. 3a, b). Thus, in Holmes' heart, the pulmonary artery and aorta appear to have a more direct anteroposterior relation than in tetralogy of Fallot. Failure to show an atrioventricular septum echocardiographically has also been reported to be a helpful sign (Chesler et al., 1970; Meyer and Kaplan, 1973). Since total correction of Holmes' heart is now feasible, every effort should be made to establish an accurate preoperative anatomical diagnosis (Edie et al., 1973).

\section{References}

Abbott, M. E. (1936). Atlas of Congenital Cardiac Diseases. American Heart Association, New York.

Anselmi, G., Muñoz Armas, S., De La Cruz, M. V., De Pisani, F., and Blanco, P. (1968). Diagnosis and classification of single ventricle. Report on seventeen cases with an anatomoembryologic discussion. American fournal of Cardiology, 21, 813-829.

Chesler, E., Joffe, H. S., Vecht, R., Beck, W., and Schrire, V. (1970). Ultrasound cardiography in single ventricle and the hypoplastic left and right heart syndromes. Circulation, 42, 123-129. 
Edie, R. N., Ellis, K., Gersony, W. M., Krongrad, E., Bowman, F. O., and Malm, J. R. (1973). Surgical repair of single ventricle. Fournal of Thoracic and Cardiovascular Surgery, 66, 350-359.

Elliott, L. P., Amplatz, K., Anderson, R. C., and Edwards, J. E. (1963). Cor triloculare biatriatum with pulmonary stenosis and normally related great vessels. American fournal of Cardiology, 11, 469-476.

Fontana, R. S., and Edwards, J. E. (1962). Congential Cardiac Disease: A Review of 357 Cases Studied Pathologically. W. B. Saunders, Philadelphia.

Holmes, A. F. (1824). Case of malformation of the heart. Transactions of the Medico-Chirurgical Society of Edinburgh, 1, 252. (Reprinted with remarks by Abbott, M. E. (1901). Montreal Medical fournal, 30, 522-532.)

Klaus, A. P., Smith, R. M., Schneider, A. B., and Parker, B. M. (1969). Single ventricle with normal relationship of the great vessels and pulmonic stenosis: a case report of an adult with the 'Holmes' heart'. American Heart fournal, 78, 530-536.

Lev, M., Liberthson, R. R., Kirkpatrick, J. R., Eckner, E. A. Q., and Arcilla, R. A. (1969). Single (primitive) ventricle. Circulation, 39, 577-591.
Marin-Garcia, J., Tandon, R., Moller, J. H., and Edwards, J. E. (1974). Common (single) ventricle with normally related great vessels. Circulation, 49, 565-573.

Meyer, R. A., and Kaplan, S. (1973). Noninvasive techniques in pediatric cardiovascular disease. Progress in Cardiovascular Diseases, 15, 341-367.

Rao, B. N. S., and Edwards, J. E. (1974). Conditions simulating the tetralogy of Fallot. Circulation, 49, 173-178.

Rosenquist, G., Olney, M., and Roe, B. B. (1963). The Holmes's heart-a variant of cor triloculare biatriatum. Report of case in a child. Circulation, 27, 1143-1147.

Van Praagh, R., Ongley, P. A., and Swan, H. J. (1964). Anatomic types of single or common ventricle in man. Morphology and geometric aspects of 60 necropsied cases. American fournal of Cardiology, 13, 367-386.

Requests for reprints to Dr. Lewis P. Scott, III, Department of Cardiology, Children's Hospital National Medical Center, 111 Michigan Avenue, N.W., Washington, D.C. 20010, U.S.A. 